\title{
A RELAÇÃO INSTRUMENTAL ENTRE HUMANIDADE E NATUREZA NO CAPITALISMO CONTEMPORÂNEO: UMA REFLEXÃO SOBRE O DIREITO INTERNACIONAL AMBIENTAL POR UMA PERSPECTIVA CRÍTICA HABERMASIANA
}

\author{
Arthur José Vieira Gomes Sales* \\ Émilien Vilas Boas Reis*" \\ Sébastien Kiwonghi Bizawu***
}

\section{RESUMO}

Este artigo, sob a ótica do direito internacional, aborda o direito ao meio ambiente sustentável, bem como o trato comumente negligente despendido a essa questão, tomando como referencial a obra de Jürgen Habermas, com o objetivo de debater soluções para a crise ambiental sistêmica a partir do agir comunicativo. Para tanto, utilizou-se de uma abordagem qualitativa, baseada no método hipotético dedutivo e na pesquisa exploratória, por meio da bibliografia pertinente. Ao final, conclui-se que a mudança do curso dessa delicada questão pode residir na crítica à maneira com que se estabelece a relação homem-natureza na sociedade contemporânea.

PALAVRAS-CHAVE: ação comunicativa; meio ambiente; capitalismo; direito internacional ambiental; Jürgen Habermas.

\section{THE INSTRUMENTAL RELATIONSHIP BETWEEN HUMANITY AND NATURE IN CONTEMPORARY CAPITALISM: A REFLECTION ON INTERNATIONAL ENVIRONMENTAL LAW FROM A HABERMASIAN CRITICAL PERSPECTIVE}

\begin{abstract}
This article, from the perspective of international law, addresses the right to the sustainable environment, and also the commonly negligent treatment of this issue, taking as reference the work of Jürgen Habermas, with the aim of debating solutions to the systemic environmental crisis through the communicative action. For that, it was applied a qualitative approach, based on the hypothetical-deductive method and exploratory research through the relevant bibliography. In the end, it is concluded that the changing on the course of this delicate issue may reside in the criticism of the way mankind-nature's relationship is established in contemporary society.

KEYWORDS: communicative action; environment; capitalism; international environmental law; Jürgen Habermas.

\footnotetext{
"Mestrando pelo Programa de Pós-Graduação em Direito Ambiental e Desenvolvimento Sustentável da Escola Superior Dom Helder Câmara $(\mathrm{BH})$. Bacharel em Direito pela mesma instituição. E-mail: arthurjvgs@gmail.com.

** Pós-doutor em Filosofia pela Universidade do Porto. Doutor em Filosofia Pela Pontifícia Universidade Católica do Rio Grande do Sul. Professor Adjunto da Escola Superior Dom Helder Câmara (BH) em nível de graduação e pós-graduação. E-mail:mboas@yahoo.com.br.

**** Pós-doutor em Democracia e Direitos Humanos pela Universidade de Coimbra. Professor Adjunto da Escola Superior Dom Hélder Câmara (BH) em nível de graduação e pós-graduação. E-mail: sebak_07@hotmail.com.
} 


\section{INTRODUÇÃO}

Desde a década de 1960, a humanidade vem tomando consciência de que se encontra em um momento crucial de sua história quanto à questão ambiental. A partir da segunda metade do século XX, a percepção das mudanças climáticas e suas multifacetadas consequências, além da compreensão acerca da finitude dos recursos naturais, tornaram evidente, no campo científico, que se impõe um novo paradigma para lidar com a questão ambiental em âmbito global, o que, desde então, se compreende na tentativa de estabelecer uma governança transnacional pautada em critérios científicos e voltada a uma conciliação de interesses.

A Conferência de Estocolmo é um marco que se pretendeu tomar como inspiração e guia "para preservar e melhorar o meio ambiente humano" (ESTOCOLMO, 1972, Preâmbulo), tomado como "um desejo urgente dos povos de todo o mundo e um dever de todos os governos". Tal conferência é considerada um referencial importante para a questão ambiental, mais por impulsionar os debates do que pela produção de resultados efetivos. De todo modo, a partir de então se tem a inserção paulatina do meio ambiente enquanto questão central a ser considerada no debate internacional. Ao final, elaborou-se um "Manifesto Ambiental", composto por novos princípios para os tempos porvir (ONU, 1972).

Trata-se de um movimento que teve seu ápice, dentre as reuniões de cúpulas governamentais, na Conferência das Nações Unidas sobre o Meio Ambiente e Desenvolvimento (também conhecida como Rio-92), com a presença de representantes de mais de 160 países, além de entidades da sociedade civil (LAVALL; OLSSON, 2019). À época, tinha-se um clima político consideravelmente mais favorável, talvez inclusive em virtude do contexto histórico de formação de um mundo multilateral. Consequentemente, alcançou-se um resultado mais relevante, inclusive pela elaboração da Agenda 21, um plano de atuação global para a questão ambiental no século presente.

Ocorre que, nas décadas seguintes, percebe-se uma atitude negligente frente a evidente gravidade da situação ambiental e dos diversos impactos sociais relacionados, os quais são extremamente danosos sobretudo para as populações mais vulneráveis. A exemplo da inefetividade das soluções até então adotadas e as diversificadas consequências ambientais e sociais, verifica-se as preocupações expressas pelo Papa Francisco (2015) na Encíclica 
Laudato si. No documento papal, aponta-se uma especial preocupação com os mais vulneráveis (BIZAWU; REIS, 2015), tema apontado pela ONU, junto da questão ambiental, como um dos principais desafios a serem superados no século XXI; ademais, vê-se uma reflexão aprofundada acerca da problemática ambiental, no contexto do modo de vida da sociedade global contemporânea, sua relação com a natureza e a técnica instrumental do progresso científico, o que será abordado no presente trabalho.

Enquanto isso, à medida que novos acordos são realizados e novas metas estabelecidas, tem-se indicativos de que, assim como ocorreu em 2012, por ocasião da Rio +20, a humanidade chegará em 2030 (termo final para implementação dos objetivos da Agenda 2030) para um novo choque de realidade diante da ineficácia de suas políticas globais. Exemplos simbólicos desse cenário desalentador são perceptíveis na ascensão de governos que negligenciam a pauta ambiental em prol dos interesses econômicos, afastando as possibilidades de elaboração de uma agenda de Estado em prol da sustentabilidade.

É a partir desse contexto de prevalência dos interesses estratégicos de determinados países e agentes políticos ou financeiros em relação às medidas protetivas ao meio ambiente, mesmo diante da urgência das questões climática e ambiental, que o presente artigo objetiva refletir sobre a contemporaneidade pela ótica do frankfurtino Jürgen Habermas. A partir de seus estudos sobre temas como a racionalidade instrumental e a democracia, propõe-se uma discussão sobre a relação entre humanidade e natureza em âmbito global, levando-se em conta as dimensões comunicativa e instrumental da razão humana.

Nessa senda, de maneira não exaustiva, o presente artigo traçou uma retrospectiva sobre a discussão ambiental em nível global, tendo em vista as preocupações que persistem na atualidade. Em seguida, analisou as considerações de teóricos críticos acerca da razão na sociedade contemporânea, alcançando, ao final, a teoria do agir comunicativo de Habermas e a relação entre as dimensões instrumental e comunicativa da razão, com suas implicações na interação entre sociedade, técnica e meio ambiente. A partir disso, buscou-se identificar tendências estruturais sobre a problemática ambiental em nível global e propor uma reflexão sobre como pensar nas adversidades inerentes ao amplo e complexo debate ambiental.

Para tanto, faz-se uma pesquisa qualitativa, pelo método hipotético-dedutivo, com abordagem exploratória a partir da análise de documentos jurídicos e um levantamento bibliográfico sobre os temas propostos, visando uma reflexão que permeie o Direito 
Internacional Ambiental e o modelo crítico de Habermas, relacionando-o ao trato da questão ambiental pela sociedade global.

\section{O DESENVOLVIMENTO DO DEBATE AMBIENTAL EM ÂMBITO GLOBAL}

A segunda metade do século XX é marcada, no direito internacional, pela expansão do debate, das conferências e dos diplomas legais protetivos ao meio ambiente, considerado um direito humano de terceira geração. Trata-se do momento histórico, após o desenvolvimento e consolidação da indústria enquanto modo de produção hegemônico, em que se começa a insurgir o imperativo da finitude dos recursos naturais e a fragilidade da biosfera diante das ações humanas, o que induz discussões acerca da melhor maneira de lidar com essa questão, algo ainda problemático. Nesse sentido, é possível afirmar que "(...) a natureza e seus valores foram um advento do século XX, originada do surgimento de um sentimento de preocupação com a proteção ao meio ambiente em prol da saúde e bem-estar do ser humano" (JAQUES, 2014, p. 3).

É momento também de difusão, aprimoramento e consolidação dos meios de comunicação de massa, com seu ápice no mundo virtual e globalizado do final do século XX. Tais fatores são propícios ao desenvolvimento, na sociedade global, de uma consciência política quanto aos danos ambientais causados pela ação humana, além da necessidade de uma reflexão ética e jurídica acerca dessa relação entre homem e natureza.

Nesse diapasão, importa fazer uma especial menção à década de 1960, momento definido por Florent Marcellesi (2008) como um "giro copernicano" na questão ambiental, com a percepção de que a pauta se relaciona, em última instância, à sobrevivência da espécie humana. Ultrapassou-se assim os fundamentos anteriores da proteção do meio ambiente, como o romantismo, a estética e a preocupação com a preservação das paisagens naturais.

Como já mencionado, a Conferência de Estocolmo foi um dos mais importantes marcos para o debate ambiental, em consequência também da movimentação da sociedade civil ao longo da década anterior. Um exemplo comumente citado são as preocupações do Clube de Roma, fundado em $1968^{\dagger}$, e que elaborou o relatório "Os Limites do Crescimento",

\footnotetext{
${ }^{\dagger}$ A esse contexto de insurgência do debate na sociedade civil, não se pode deixar de acrescentar os movimentos estudantis de Maio de 1968, ocorridos sobretudo na França, marcados por uma forte negação dos valores, do modo de produção e, sobretudo, da ideologia vigente em uma sociedade de mercado industrializada. Sobre esse contexto histórico, Florent Marcellesi afirma que, dentre os diversos movimentos que fervilhavam na europa
} 
um dos objetos de discussão na Conferência (LAVALL; OLSSON, 2015). Embora tenha sido marcado por um forte embate político entre os países do Norte e Sul global, foi nessa ocasião que se elaborou o Programa das Nações Unidas para o Meio Ambiente (PNUMA).

A partir disso, têm-se a proliferação de documentos jurídicos internacionais acerca do meio ambiente e se inicia uma construção doutrinária desse novo campo jurídico (FERRER; GLASENAPP; et al, 2014). Desde o princípio esse movimento se pautou na concepção de proteção das gerações presentes e futuras, numa perspectiva de solidariedade internacional que seria consolidada no Relatório Brundtland. Ademais, inicia-se um fenômeno de constitucionalização do direito ambiental no âmbito soberano de vários estados nacionais, o que denota a formação de um novo paradigma jurídico político acerca dos direitos difusos e da sustentabilidade. Tal fenômeno é compreendido por Meadowcroft (2012) como o "esverdeamento" dos Estados e tem seu ápice a partir da década de 1980.

Com enfoque planetário, começa a se desenvolver uma ideia de governança do meio ambiente, justamente por se tratar - em última análise - de uma crise ambiental que, necessariamente, deve ser pensada em âmbito global, em busca de uma cooperação internacional:

\footnotetext{
Com o amadurecimento, a mãe Terra passa a ser compreendida pelo direito internacional do meio ambiente como um único ambiente, não mais limitado em fronteiras políticas. Resultado da conscientização de que é imprescindível unificar os vários meios ambientes - local, regional, nacional, internacional - de forma a facilitar sua proteção em um único sistema normativo. (FERRER; GLASENAPP $e t$ $a l, 2014)$.
}

Partindo dessa perspectiva, verifica-se um fenômeno de difusão do poder estatal do âmbito interno para entidades supranacionais e também, no âmbito interno, para grupos subnacionais (LAVALL; OLSSON, 2019). Isso passa por uma discussão em relação ao conceito e abrangência da soberania estatal e, na prática, encontra empecilhos na medida em que, pela própria dinâmica de funcionamento das democracias liberais, torna-se muito difícil verificar uma coesão global no assunto, com a formação de agendas de Estado, e não meramente de governo, voltadas à proteção ambiental.

ocidental, uma perspectiva ecologista também ganhava espaço, relacionada a uma crítica ao modelo produtivista de sociedade. 
Nesse cenário, ante a insuficiência das medidas até então tomadas para o combate à degradação ambiental, outro documento histórico relevante foi o relatório da Comissão de Brundtland (1987), intitulado "Nosso Futuro Comum”, já mencionado alhures. Esse episódio motiva a convocação de uma nova conferência pela Assembleia Geral das Nações Unidas, para, então, dar prosseguimento às tratativas por um novo paradigma de desenvolvimento que integre a sustentabilidade ambiental, "contudo sem perder enfoque da perspectiva econômica, ou melhor, do desenvolvimento e das disparidades de níveis econômicos existentes entre os países." (JAQUES, 2014, p. 11).

Nesse mesmo contexto, tem-se a inserção da questão climática no debate público internacional, por ocasião da Conferência de Toronto (1988), com a apresentação de estudos acerca da relação entre emissão de gases poluentes e o efeito estufa, além da criação do Painel Intergovernamental sobre Mudanças Climáticas (NAVES; PIRES, 2018). E é desse cenário que, por fim, ocorre a conhecida Conferência das Nações Unidas sobre o Meio Ambiente, ou Rio 92.

Nota-se a incorporação, na declaração final, do princípio das responsabilidades comuns, porém diferenciadas, e a elaboração da conhecida Agenda 21, além de outras declarações assinadas na ocasião. Nessa perspectiva, conforme Lavall e Olsson (2019), estabeleceu-se um plano de ação composto por 40 capítulos e segmentado em quatro eixos: áreas social e econômica, conservação e gestão de recursos, a transição para o desenvolvimento sustentável e os meios de implementação.

Jaques (2014) explica que, nesse momento, procura-se uma conciliação entre a proteção ambiental, a redução de desigualdades sociais e, por fim, a eficiência econômica. Contudo, pode-se acrescentar que se mantem uma perspectiva ambientalista que é problemática por olvidar de alguns aspectos da lógica produtiva vigente e seus impactos climáticos e ambientais, o que é considerado um ponto chave da discussão por algumas correntes teóricas, a exemplo da ecologia política".

Apesar disso, como explica o autor supracitado, não se trata de um documento jurídico internacional dotado de força normativa, assim como tratados e convenções, podendo ser compreendido melhor como um conjunto de prioridades e diretrizes políticas para a

\footnotetext{
* Tem-se, na ecologia política, uma abordagem da questão ambiental em que se pauta a necessidade de uma reforma qualitativa do modo de produção que provoca a degradação do ambiente, conforme explica Marselessi (2008).
} 
promoção do desenvolvimento sustentável em nível global, a partir da cooperação multilateral entre Estados.

\subsection{Perspectivas atuais da situação climática e a proteção internacional ambiental}

Ao analisar o decurso histórico do sistema ONU de governança ambiental, Sequinel (2002) afirma que, na Agenda 21, prescreve-se uma descrição de desenvolvimento sustentável em que se impõe mudanças aos valores e instituições vigentes, o que deveria ser verificável ao longo dos anos.

A autora cita como, na Rio +5 (em 1997), verificou-se uma série de lacunas que exigiam atenção para realização da Agenda 21, sobretudo no tocante à equidade social e redução da pobreza. Com isso, reforçou-se a necessidade de uma continuidade do projeto concebido na Rio 92.

Cinco anos após, a Cúpula Mundial sobre Desenvolvimento Sustentável, conhecida como Rio +10 , sediada em Johanesburgo, no ano de 2002, foi marcada por um clima totalmente diverso da Conferência de 1992, com um significativo conflito de interesses das partes, sobretudo acerca de propostas modificativas da matriz energética mundial (LAVALL; OLSSON, 2019), de modo que as propostas de Brasil e União Europeia sobre energia foram rejeitadas por países que eram grandes produtores de petróleo.

Dando continuidade a essa breve retrospectiva, Gomes e Ferreira (2018) explicam que, mais recentemente, na Rio +20 , o que ocorreu foi um prosseguimento do debate público acerca da redução da pobreza, com uma inserção mais profunda na ideia e na promoção do desenvolvimento sustentável, adentrando-se também na questão de uma economia verde. Manteve-se uma perspectiva conciliatória do desenvolvimento e preservação ambiental; contudo, voltou-se também "para a dimensão social, econômica, ética e jurídico-política" (GOMES; FERREIRA, 2018, p. 160), de modo a englobar qualquer atividade voltada ao equilíbrio dessas dimensões.

Não obstante, a Conferência de 2012 também trouxe apontamentos acerca do andamento das soluções propostas para lidar com a iminente crise ambiental, sendo perceptível que tais diagnósticos não foram positivos: 
A terceira grande conferência da ONU sobre desenvolvimento sustentável, a Rio +20, realizada em 2012, escancarou um paradoxo tão real quanto indesejável: a existência de uma "[...] enorme lacuna entre onde a ONU gostaria que o mundo estivesse e onde ele realmente se encontrava" (CARADONNA, 2016, P.156). Nessa senda, a conferência foi marcada por lamentações sobre os esforços fracassados para a transição ao tipo de ordem global sustentável previsto em 1992, mas, também, pela renovação do compromisso político com a causa da sustentabilidade. (LAVALL; OLSSON, 2019, p. 57, grifo nosso).

Ademais, em termos propositivos, Guimarães e Fontoura (2012) explicam que pouco se avançou na Rio +20 , que se limitou a produzir a declaração política "O Futuro que Queremos", qualificada por eles como vaga, e cujo texto original foi extremamente reduzido e aprovado ainda com uma série de restrições. Para os autores, isso denota uma ausência de interesse político global para a promoção de mudanças substanciais, priorizando-se os interesses financeiros e a não afetação ao modo de vida de suas populações. Nesse sentido:

\begin{abstract}
Ativistas e estudiosos são unânimes em advertir que nada menos do que uma nova ética planetária deve emergir se quisermos sobreviver como espécie (GUIMARÃES, 1991, 2001). Esta transição à sustentabilidade requer transformações profundas no arquétipo dominante de civilização, em especial no que tange ao padrão cultural de articulação entre os seres humanos e a natureza. (...).

É preciso, portanto, que o entendimento adequado sobre a transição reconheça que a humanidade aproxima-se rapidamente, se é que já não sofre os resultados, do esgotamento de um estilo de desenvolvimento ecologicamente depredador (exaurindo a base natural de recursos), socialmente perverso (gerando pobreza e desigualdade), politicamente injusto (congelando a escassez relativa e absoluta no acesso aos recursos), eticamente reprovável (desrespeitando as formas de vida humana e não-humanas) e culturalmente alienado (produzindo o estranhamento entre os seres humanos e subjugando a natureza). (GUIMARÃES; FONTOURA, 2012, p. 20. grifo nosso)
\end{abstract}

Essa diretriz justifica a guinada que se perceberá adiante neste artigo, sustentando a necessidade de uma reflexão crítica sobre o contexto estrutural da sociedade e o trato desta com a natureza, bem como a maneira com que se compreende e se racionaliza a questão ambiental, assim como as noções de desenvolvimento e progresso.

\title{
3 A NECESSIDADE DE UMA REFLEXÃO CRÍTICA AMBIENTAL E O MODELO HABERMASIANO COMO UMA POSSIBILIDADE DE ESCLARECIMENTO
}

Na já mencionada Encíclica Laudato Si, Papa Francisco (2015) afirma, sobre as mudanças climáticas: 
23. O clima é um bem comum, um bem de todos e para todos. A nível global, é um sistema complexo, que tem a ver com muitas condições essenciais para a vida humana. Há um consenso científico muito consistente, indicando que estamos perante um preocupante aquecimento do sistema climático. Nas últimas décadas, este aquecimento foi acompanhado por uma elevação constante do nível do mar, sendo difícil não o relacionar ainda com o aumento de acontecimentos meteorológicos extremos, embora não se possa atribuir uma causa cientificamente determinada a cada fenómeno particular. A humanidade é chamada a tomar consciência da necessidade de mudanças de estilos de vida, de produção e de consumo, para combater este aquecimento ou, pelo menos, as causas humanas que o produzem ou acentuam. (PAPA FRANCISCO, 2015, p. 8).

O pontífice aponta na questão das mudanças climáticas e, em outras passagens, na problemática ambiental como um todo, uma necessidade de se refletir acerca da ação humana sobre o meio ambiente. Mais do que isso, o Papa demonstra uma preocupação nítida com os fundamentos desse comportamento autodestrutivo que se pode perceber atualmente em todas as sociedades.

Em sua exposição, ele dedica um capítulo inteiro à análise da raiz humana na crise ecológica, e reflete sobre o "paradigma tecnocrático dominante e no lugar que ocupa nele o ser humano e sua ação no mundo" (PAPA FRANCISCO, 2015, p. 32). Ademais, discute-se o paradigma de mundo e cultura em que estamos inseridos, além da forma com que a sociedade age sobre as subjetividades, de modo que

(...) na origem de muitas dificuldades do mundo actual (sic), está principalmente a tendência, nem sempre consciente, de elaborar a metodologia e os objectivos (sic) da tecnociência segundo um paradigma de compreensão que condiciona a vida das pessoas e o funcionamento da sociedade. (...). É preciso reconhecer que os produtos da técnica não são neutros, porque criam uma trama que acaba por condicionar os estilos de vida e orientam as possibilidades sociais na linha dos interesses de determinados grupos de poder. Certas opções, que parecem puramente instrumentais, na realidade são opções sobre o tipo de vida social que se pretende desenvolver.

(...) Não se consegue pensar que seja possível sustentar outro paradigma cultural e servir-se da técnica como mero instrumento, porque hoje o paradigma tecnocrático tornou-se tão dominante que é muito difícil prescindir dos seus recursos, e mais difícil ainda é utilizar os seus recursos sem ser dominados pela sua lógica. (PAPA FRANCISCO, 2015, p. 34, grifo nosso).

Tal análise parte do pressuposto de que, na formação da subjetividade do ser humano e na forma com que ele se relaciona com a sociedade e o mundo, há todo um contexto préexistente, dotado de uma série de fatores que são determinantes e se impõem à sua individualidade. 
Essa noção foi compreendida, por exemplo, na obra marxiana, e sintetizada em seu método conhecido como materialismo histórico, em que se reconhece que o conjunto de relações de produção, em determinado momento histórico, condiciona "o desenvolvimento da vida social, política e intelectual em geral" (MARX, 2015). Trata-se de uma das principais influências à teoria crítica, campo teórico em que Habermas se situa.

Em outras palavras, entende-se que o ser humano, enquanto agente social, não é totalmente livre, pois ele já se encontra em determinado contexto histórico e econômico que se impõe ao seu agir e à sua forma de ver e lidar com o mundo; no caso de Marx, à sua época, esse contexto era o da formação da sociedade capitalista, a partir do que o autor desenvolveu sua crítica à economia política.

Assim, tratando especificamente da teoria crítica, para que se possa contextualizar pensamento de Habermas, cumpre primeiro passar por um breve percurso, conforme se verá adiante.

Max Horkheimer, autor da obra "Teoria Tradicional e Teoria Crítica", foi um dos principais representantes e dirigentes da Escola de Frankfurt, uma das mais influentes correntes do marxismo no século XX, e é identificado por Marcos Nobre (2011) como o responsável por estruturar o que seria esse campo teórico.

Segundo Nobre (2011), há uma série de características que distinguem a teoria crítica do que seria, na nomenclatura de Horkheimer, uma teoria tradicional. Talvez a mais crucial dessas diferenças seja a de que, no campo teórico crítico, parte-se do argumento de que a pretensa neutralidade das ciências humanas sob um paradigma positivista, em que se importa irrefletidamente para as ciências do espírito pressupostos de objetividade das ciências naturais, resultaria na realidade em um posicionamento parcial em prol do estado de coisas existente.

É por isso que, ao lidar com a sociedade, Nobre (2011) explica que o pensamento crítico adota a compreensão de que não se pode tratar do ser se abdicando do dever-ser. Desse modo, é preciso uma análise voltada aos potenciais inscritos na própria realidade social, suas contradições, falhas e ilusões, para então identificar suas tendências, o que se compreende como o conflito entre os potenciais emancipatórios e os elementos fáticos que impedem sua concretização.

Basicamente, parte-se aqui do pressuposto de que as ciências humanas não devem se limitar à mera explicação de relações causais, formulando teorias e prognósticos, como ocorre 
nas ciências da natureza. A teoria social cumpre um papel político relevante, na medida em que fundamenta uma praxis transformadora diante da estrutura social existente. Essa prática, por sua vez, torna-se um elemento da própria teoria, em uma negação da dicotomia autoevidente da separação entre teoria e prática, na medida em que lançará as bases para o desenvolvimento teórico ao longo de novas formas históricas.

Ora, considerando esses fatores, o paradigma científico da teoria crítica parece constituir uma base razoável para o pensamento em relação à questão ambiental, uma das mais urgentes contradições inerentes ao modo de produção vigente, a qual deve ser compreendida tendo em vista a necessidade de uma emancipação socioambiental. Desse modo, a teoria científica e o conhecimento em geral assumem uma função política relevante, numa contemporaneidade pautada pelo progresso técnico como fim único da sociedade. Nesse cenário, a crise iminente é um imperativo para se buscar respostas por meio de uma atitude crítica.

Como discorre Ulrich Beck (2011), encontramo-nos numa "modernidade tardia" em que somos afetados que produzem danos por vezes irreversíveis, que “(...) permanecem no mais das vezes fundamentalmente invisíveis, baseiam-se em interpretações causais, [e] apresentam-se portanto tão-somente no conhecimento" (BECK, 2011, p. 27).

A partir disso, pode-se retomar a encíclica papal que abriu este capítulo, para frisar a importância da reflexão levantada pelo pontífice a respeito do trato e da relação que o homem estabeleceu com a natureza, que se torna instrumentalizada - conforme a racionalidade dominante dos sistemas econômicos e políticos - para servir de substrato à uma concepção por vezes irrefletida de desenvolvimento. É o que a tradição marxista identificaria como reificação da natureza, o processo em que tal ente é destituído de sua essência e submetido à condição de uma coisa, manipulável pela técnica humana. Assim, mesmo quando se busca uma solução e uma ressignificação do modelo de desenvolvimento, a natureza segue sendo qualificada enquanto mero recurso para o desenvolvimento.

É forçoso reconhecer, portanto, a validade do questionamento de em que medida os acordos e tratativas globais, abordados na primeira parte desse artigo, serão suficientemente efetivos nessa perspectiva de conciliação das imposições do desenvolvimento econômico com as imposições da crise ambiental.

A partir disso, já em outro patamar reflexivo, pode-se abrir uma série de questionamentos sobre o que tem sido feito até então, escrutando-se inclusive se a própria 
ideia de desenvolvimento seria inconciliável com a de sustentabilidade, hipótese defendida por diversos autores, a exemplo de Ronaldo Coutinho (2010), que, sob uma perspectiva marxista ortodoxa, sustenta ser parte da essência do capitalismo a transformação da natureza substrato de todos os valores de uso - em mercadorias. Portanto, na visão do autor, teorias que não proponham uma superação total do atual modo de produção não passariam de "utopias liberais". Sob essa ótica, o Direito é compreendido com um produto da realidade social, e não seu construtor, de maneira que a ordem jurídica seria mais um dos elementos a compor uma superestrutura que se impõe aos indivíduos e lhes limita a autonomia e a liberdade.

Decerto, apesar da importância dessa constatação, não se pode descartar que atualmente a humanidade se encontra, em comparação à época de Marx, num momento diverso e muito mais complexo da sociedade global, o que implica no surgimento de novas tendências históricas. Para refletir sobre o assunto, serão retomados alguns apontamentos da primeira geração da Escola de Frankfurt acerca da racionalidade instrumental e o caráter progressivamente complexo do capitalismo de sua época, para que em seguida sejam trabalhados os apontamentos de Habermas sobre o agir comunicativo e sua relação com os potenciais de uma democracia deliberativa, o que será crucial para tratar da relação homemnatureza diante da crise ambiental.

\subsection{Controle social e racionalidade instrumental no mundo contemporâneo}

Em seu ensaio “A Teoria Crítica entre o Nazismo e o Capitalismo Tardio”, Marcos Nobre (2008) trata sobre o desenrolar do pensamento Frankfurtiano na primeira metade do século XX, momento em que Adorno e Horkheimer se preocupam com uma reflexão de cunho antropológico para sua época, com a estrutura da razão e também com as influências disso na relação do homem com o seu meio. Habermas (2012), por sua vez, explica que Adorno e Horkheimer iniciaram seus trabalhos refletindo sobre o fascismo e seus mecanismos psíquicos; posteriormente, contudo, transitam para um pensamento político acerca da teoria da cultura de massa, voltando-se "aos fenômenos não tão espetaculares de uma integração social da consciência acerca dos meios de comunicação de massa". (HABERMAS, 2012, p. 637). 
Basicamente, numa busca pelas condições materiais que possibilitassem a organização revolucionária das classes exploradas, os autores manifestaram uma preocupação teórica com os fenômenos que, então, constituíam verdadeiros empecilhos à insurgência da postura radical por eles defendida. Na Europa, o exemplo patente disso foi a ascensão de regimes totalitários de extrema-direita, como o fascismo e nazismo. No entanto, o diagnóstico dos autores não se limita a esses fenômenos flagrantemente antidemocráticos.

Isso porque o bloqueio da praxis emancipatória passa a ser observável de maneira geral no capitalismo do século XX, com a expansão e estabilização desse sistema econômico a partir de sua relação com Estado. O que se percebe, então, é um controle político das crises intrínsecas ao sistema capitalista, desmobilizando-se a classe explorada. Junto disso, outro conceito muito caro aos estudos de Adorno e Horkheimer, e aos teóricos críticos de maneira geral, é o da integração social por meio de uma racionalidade instrumental, o qual será aprofundado adiante. A partir disso se pode divisar variados aspectos da vida em sociedade, inclusive o trato com o meio ambiente.

Os autores trabalham essa análise na obra "Dialética do esclarecimento" (2014), publicada originalmente em 1947. É uma década importante para o desenvolvimento da teoria crítica, fortemente marcada pela segunda guerra, o nazismo, a bomba atômica, as sucessivas crises do capitalismo, entre outros fatores que, em comum, levavam as ciências sociais à uma necessária revisão acerca das potencialidades destrutivas do progresso técnico-científico até então experimentado.

É também o momento de insurgência dos meios de comunicação de massa: a rádio, a televisão e o cinema integram a cultura do capitalismo estadunidense, onde os autores residiram durante a guerra, e logo se expande para outros locais do centro do capitalismo global. Esse é um elemento essencial da obra, que dedica um de seus ensaios à análise da indústria cultural e sua importância para manutenção do estado de coisas. Basicamente, a partir do momento em que a arte se torna uma mercadoria, essa adquire um valor de troca que lhe é limitador. Com isso, percebe-se uma inserção dessa esfera da vida humana em uma lógica mercadológica que lhe modifica substancialmente, tolhendo-lhe o potencial de negação da facticidade.

Isso é exemplar desse processo de integração e controle em um capitalismo de estágio avançado: essa lógica mercadológica, pautada em uma racionalidade instrumental, envolve-se com todas as esferas da vida e lhes impõe a dinâmica própria de uma mercadoria. 
É um fenômeno perceptível na esfera social, cultural, familiar e, inclusive, no trato com o meio ambiente.

Cumpre esclarecer que, por racionalidade instrumental, compreende-se esse paradigma em que a razão deixa de se ocupar com os fins a serem alcançados socialmente, mas passa a servir tão somente como um meio para obtenção desses fins. A partir disso, os autores buscaram compreender o porquê de o ideal iluminista não ter proporcionado uma sociabilidade livre e igualitária, mas sim “(...) um sistema social que bloqueou estruturalmente qualquer possibilidade emancipatória e transformou os indivíduos em engrenagens de um mecanismo que não compreendem e não dominam, e ao qual se submetem e se adaptam impotentes" (NOBRE, 2011, p. 51-52).

Percebe-se, portanto, a constatação de uma queda no paradigma de liberdade e ação do ser humano, assim como da possiblidade de se atuar efetivamente sobre seu meio. Nessa perspectiva, os indivíduos nascem e são criados em uma sociedade que, de maneiras diversas, impõe certos padrões de conduta, comportamento e pensamento, orientados dentro de uma moldura adequada ao sistema vigente. E é a partir disso que os autores constatam esse bloqueio de potenciais emancipatórios, que decorre diretamente desse complexo boicote a uma atitude crítica, pela sujeição dos indivíduos a variadas necessidades.

Sem adentrar a um juízo de correição desse diagnóstico, vale a reflexão de que, quando aplicado à questão ambiental, os contornos se tornam ainda mais problemáticos. Afinal, nessa perspectiva se pensa em uma sociedade condicionada a certos padrões de vida e de consumo que são contraditórios com as limitações ambientais. Sob essa ótica, fatalmente se chega à conclusão da insuficiência de propostas como a solidariedade intergeracional ou um desenvolvimento sustentável, ao menos sem antes se trabalhar as complexas relações sociais envolvidas.

De fato, como refletem Jürgen Habermas (2012) e Marcos Nobre (2011), Adorno e Horkheimer, com o diagnóstico do mundo administrado e o bloqueio estrutural da praxis, chegaram a uma aporia do pensamento crítico. É necessário, portanto, uma solução não aporética para a crise socioambiental, que adquire contornos progressivamente mais urgentes; contudo, sem se abdicar de uma atitude crítica em face das relações sociais.

\section{2 $O$ agir comunicativo e o mundo da vida em Habermas: bases para se construir uma nova perspectiva de sociedade?}


Para Habermas, ao chegarem na aporia supramencionada, seus mentores assumiram um ceticismo que lhes impediu de elaborar um pensamento crítico dotado de pretensões emancipatórias. Vale lembrar que a teoria crítica tem em sua essência uma mutabilidade, que decorre do caráter histórico de sua análise. Portanto, exige-se do pesquisador uma atitude crítica voltada à sua época, e isso se aplicaria também à própria ideia de emancipação, que, a partir de Habermas, assumiria um rompimento completo com a perspectiva revolucionária marxista (NOBRE, 2011).

As divergências de Habermas, contudo, não se fundamentam na negação do diagnóstico de seus antecessores da Escola de Frankfurt, mas sim em uma divergência acerca das conclusões extraíveis dessa dimensão histórica que habilmente analisaram. Nas palavras do autor:

\begin{abstract}
Gostaria de não me aprofundar nessa teoria; ela continuou sendo interessante, mas antes em função de seu questionamento geral do que em função de suas hipóteses individuais. Adorno assumiu uma perspectiva de crítica cultural que com razão the conferiu um tom cético. (...). Por outro lado, Adorno não dispõe de um conceito claro sobre o caráter ambivalente de um controle social exercido sobre os meios de comunicação de massa, como veremos. (HABERMAS, 2012, p. 639, grifo nosso).
\end{abstract}

Basicamente, Habermas reconhece que o capitalismo fortalece as forças produtivas em detrimento das "forças de resistência subjetiva"; contudo, vê um potencial emancipatório na medida em que possam coexistir a razão instrumental, a serviço da autopreservação do sistema, e a razão comunicativa, que propicia uma possibilidade de problematização e modificação do mundo da vida. Nesse sentido, ele continua:

Enquanto o medium dinheiro substitui o entendimento por via linguística como mecanismo de coordenação de ações, os meios de comunicação de massa continuam dependentes do entendimento alcançado pela linguagem. Esses meios constituem reforçadores técnicos da comunicação verbal, os quais suplantam distâncias no tempo e no espaço, multiplicam as possibilidades comunicativas, torna mais densa a rede do agir comunicativo, sem no entanto desacoplar entre si as orientações da ação e os contextos ligados ao mundo da vida. Por certo, o potencial comunicativo enormemente ampliado é neutralizado de início por formas de organização que asseguram fluxos de comunicação de mão única, portanto, não reversíveis. Mas, se a cultura de massa feita sob medida para os meios de comunicação é capaz de desenvolver força suficiente para a integração regressiva da consciência, isso depende primeiramente de "a comunicação (promover) a equiparação dos seres humanos por meio do isolamento deles"; e não depende, por outro lado, de as leis do 
mercado intervirem sempre mais profundamente na produção cultural. (HABERMAS, 2012, p. 639-640).

Fortemente influenciado pela fenomenologia e pela produção teórica da virada linguística, o filósofo procura identificar, no agir comunicativo, as condições necessárias para uma racionalização do mundo da vida, que se comporta, perante o indivíduo, como uma moldura de aspectos objetivos, sociais e subjetivos. (HABERMAS, 2012b).

Isso porque, como dito, o autor não trata da racionalidade instrumental como o grande problema da contemporaneidade. Para ele, são dimensões diversas da razão, e a instrumental cumpre um papel para a sociedade, sobretudo no tocante ao progresso e à técnica. O real problema, então, reside quando há uma confusão entre essas manifestações distintas da razão, sendo que a instrumental, própria do capitalismo, sobrepõe-se à razão comunicativa, o que o filósofo identifica como uma patologia social.

Essa constatação é explicada por Luiz Repa (2009). Segundo o autor, é a partir dessa sobreposição indevida que ocorre uma dominação do mundo da vida pela lógica colonizadora que o autor identifica como um sistema subdividido entre poder e dinheiro. Daí se tem o conceito habermasiano de colonização sistêmica do mundo da vida.

Desse modo, encontra-se uma tendência estrutural a impedir a construção de uma nova relação entre humanidade e meio ambiente, a qual se encontra pautada por critérios de racionalidade próprios dos sistemas econômico e político. Ao que tudo indica, há o domínio de uma razão teleológica, cujos fins são estranhos à natureza e aos indivíduos, submetendo-os à categoria de instrumentos da lógica produtiva, como se pode constatar no desenrolar histórico das ações de governança ambiental global.

\subsection{A crise ecológica e a necessidade de uma racionalidade ambiental enquanto ponto de partida para as políticas globais}

O mundo da vida, enquanto um local pré-existente aos sujeitos de fala e por eles compostos, uma vez colonizado pelo sistema, num sentido habermasiano, é uma estrutura tendente à manutenção do status quo de uma maneira geral. Mas isso não significa que seja uma instância intangível.

Como dito, Habermas é crítico da constatação cética de seus predecessores, e pensa na racionalidade comunicativa como uma possiblidade de ressignificar e problematizar 
elementos do mundo da vida. Ou seja, o filósofo identifica uma possível emancipação em relação à ideologia e às estruturas dominantes, a partir de uma pragmática comunicativa.

Todavia, talvez uma das principais análises que se possa retirar desse estudo crítico, e em uma correlação com o Direito Internacional Ambiental, é no sentido de que não se pode esperar solucionar uma questão complexa como a da crise ambiental sem, simultaneamente, promover uma reconstrução do contexto em que se está inserido, nos diversos espectros do mundo da vida.

Desse modo, pelos elementos trazidos neste artigo, pode-se criticar o paradigma de desenvolvimento sustentável vigente, na medida em que se elabora uma concepção abstrata para a solução da crise ambiental sem antes enfrentar o contexto em que se insere a sociedade a que essas normas são destinadas.

Mas a questão vai além. Fora do contexto político institucional global, é preciso refletir sobre as complexas formas de reprodução do sistema em um capitalismo tardio, para usar a terminologia de Adorno e Horkheimer, e as formas de integração dessas sociedades.

Essa observação não significa um alinhamento à posição dos autores ao assumirem uma postura cética, como definiu Habermas, quanto às possibilidades de emancipação. Mas é preciso reconhecer que há um contexto cultural, social e subjetivo que não pode ser deixado de fora da análise, para então se propor as reformas necessárias. No caso, esse contexto se caracteriza por indivíduos e sociedades que se desenvolvem incentivados a se tornarem empregados e consumidores, servindo de maneira instrumental à uma lógica produtivista do capitalismo.

Então, para além de se pensar em uma proposta de solução de compatibilização entre desenvolvimento e sustentabilidade, como é o cenário atual, seria necessária uma reflexão sobre como é possível, nesse contexto, desenvolver condições propícias à uma verdadeira prática comunicativa emancipadora, que abarque os aspectos supracitados, e em âmbito global.

Para tanto, é importante considerar as condições ideias de fala de Habermas, o que ele aponta como necessário para o agir comunicativo e a identificação de legitimidade nas conclusões alcançadas intersubjetivamente. Nesse sentido, o autor indica que a ação comunicativa se distingue da estratégica e da instrumental, uma vez que possui, como précondições para sua efetivação, que os sujeitos estejam em pé de igualdade, livres de coação e interessados apenas no melhor argumento para motivar seu convencimento (REPA, 2009). 
Evidentemente, isso é algo inobservável na realidade. Apesar disso, trata-se de condições a serem antecipadas pelos participantes de qualquer debate racional. E talvez a ausência de preocupação com essas pré-condições, irrefletidas no debate ambiental global, em sede de tratados e instituições, seja parte do problema do que foi feito até os dias atuais.

Pelo que se demonstrou na primeira parte do artigo, vários debates necessários foram deixados de lado e subjugados por interesses políticos e econômicos das partes envolvidas, o que foi prejudicial para pautas como a substituição de combustíveis fósseis e a regulamentação de créditos de carbono. Como afirma Papa Francisco, a "submissão da política à tecnologia e à finança demonstra-se na falência das cimeiras mundiais sobre o meio ambiente. Há demasiados interesses particulares e, com muita facilidade, o interesse económico chega a prevalecer sobre o bem comum" (PAPA FRANCISCO, 2015, p. 18).

Importa observar que, quando Habermas traz suas análises para o âmbito prático do direito e da democracia, ele trabalha com o conceito de "democracia deliberativa", a partir da qual se desenvolve uma concepção de política pautada em uma "legitimidade democrática", a qual depende de certos aspectos qualitativos dos processos decisórios em determinada sociedade, para sua justificação pública (SILVA, 2008). Segundo essa concepção, Felipe Silva (2008) explica que as relações comunicativas são o primeiro momento de formação da vontade política, trata-se de uma esfera pública não institucional, que constitui pautas a serem levadas às instituições político-decisórias.

Além disso, o conceito de democracia deliberativa abrange, também, uma percepção de democracia procedimental, no sentido de que as decisões somente são legítimas quando tomadas por processos dialógicos capazes de produzir entendimentos justos. Nesse sentido, exige-se um procedimento capaz de permitir a participação das partes interessadas, em condições de liberdade e igualdade, o que se compreende como um pragmática voltada, conforme Costa e Reis (2016), a uma "base universal de validade".

A partir dessa explanação sobre o conceito habermasiano de democracia e legitimidade procedimental, surge um apontamento: é insuficiente, para solucionar a crise ambiental, conceber uma visão diversa de desenvolvimento e simplesmente aplicá-la a um sistema pautado por uma racionalidade econômica dominante. Há um cenário patológico na contemporaneidade no que diz respeito à relação humanidade-natureza, com a sobreposição dessa racionalidade econômica sobre todos os âmbitos da vida: 
A hegemonia da racionalidade econômica, comandada pelo mercado, tem por objetivo a reprodução do capital para alcançar unicamente o lucro. Nesse sistema, a sociedade é vista tão somente como mercado consumidor, a natureza como recurso, matéria-prima para fabricação dos produtos, que, por sua vez, rapidamente tornamse obsoletos, permitindo que a engrenagem capitalista continue a se reproduzir. As consequências dessa racionalidade, entre outras, é a profunda crise ambiental experimentada nesse início de século, por meio do aquecimento global, do efeito estufa, da redução da camada de ozônio, da degradação da terra e da água, do acúmulo de resíduos, toda espécie de poluição, destruição da biodiversidade, aumento populacional, fatores que colocam todo o ecossistema global em risco. (STEFANIAK, 2016, p. 76, grifos no original).

Evidentemente, isso não significa dizer que as medidas até então tomadas foram inúteis, e a autora, inclusive, reconhece a importância dos avanços do debate acerca da crise ambiental; contudo, aponta que "não foi suficiente para engajar as nações em busca da construção da racionalidade ambiental, que exige medidas muito mais severas do que as soft law produzidas no âmbito internacional”. (STEFANIAK, 2016).

\section{CONSIDERAÇÕES FINAIS}

A título de reflexões finais, cumpre frisar a necessidade de uma atitude crítica acerca dos parâmetros em que se constrói uma política pública global numa vertente ambientalista. Como se buscou abordar (brevemente, em virtude das limitações de um artigo), a partir de uma análise crítica aparentemente há duas constatações possíveis acerca da crise ambiental no século XXI.

Em uma primeira análise, falta esperança quanto à uma possibilidade de se efetivar uma política efetiva para o trato da natureza. Contudo, ao longo dessas páginas se buscou demonstrar que a possibilidade de modificação do curso dessa delicada questão pode residir numa reflexão primária quanto a maneira com que se estabelece a relação homem-natureza no capitalismo contemporâneo, e na tentativa de primeiramente modificar essa perspectiva, ao invés de mantê-la e apenas buscar remediá-la.

Sob uma nova ética ambiental global, como a proposta pelo Papa Francisco, e por meio de condições procedimentais que permitam construí-la, talvez resida o fio de esperança para a crucial Agenda do Séc. XXI. Construir tais condições, sob uma realidade de distribuição tão desigual de recursos, poderio político e econômico, é o grande desafio que se apresenta, cuja superação impõe uma ação coletiva, nas diversas dimensões sociais. 


\section{REFERENCIAS}

ADORNO, Theodore W.; HORKHEIMER, Max. Dialética do esclarecimento, Rio de Janeiro: Jorge Zahar, 2014. [E-book]

BECK, Ulrich. Sociedade de risco: rumo a uma outra modernidade. São Paulo: Editora 34, $2^{\mathrm{a}}$ ed. 2011.

BIZAWU, Kiwoghi; REIS, Émilien Vilas Boas. A Encíclica Laudato Si à luz do Direito Internacional do Meio Ambiente. Revista Veredas do Direito, Belo Horizonte, v. 12, n 23, p. 29-65, jan/jun, 2015.

COMISSÃO MUNDIAL SOBRE MEIO AMBIENTE E DESENVOLVIMENTO. NOSSO FUTURO COMUM. Rio de Janeiro: Editora da Fundação Getúlio Vargas, 1991.

COSTA, Beatriz Souza; REIS, Émilien Vilas Boas; OLIVEIRA, Márcio Luís. Fundamentos filosóficos e constitucionais do direito ambiental. Rio de Janeiro: Lumen Juris, 2016.

COUTINHO, Ronaldo. Sustentabilidade e capitalismo: elementos para uma análise marxista. In BELLO, Enzo (Org). Direito e Marxismo: as novas tendências constitucionais da América Latina. Caxias do Sul: EDUSC, 2010.

FERRER, Gabriel Real; GLASENAPP, Maikon Cristiano; CRUZ, Paulo Márcio. SUSTENTABILIDADE: UM NOVO PARADIGMA PARA O DIREITO. Revista Novo Estudos Jurídicos, Itajaí/SC, v. 19, n 4, p. 1443-1464, 2014.

GOMES; Magno Frederici; FERREIRA, Leandro José. Políticas Públicas e os Objetivos do Desenvolvimento Sustentável. Direito e Desenvolvimento, João Pessoa, v. 9, n. 2, p. 155 178, ago/dez, 2018.

GUIMARÃES, Roberto Pereira; FONTOURA, Yuna Souza dos Reis da. Rio + 20 ou Rio 20 ? Crônica de um fracasso anunciado. Disponível em:

<https://www.scielo.br/pdf/asoc/v15n3/a03v15n3.pdf>. Acesso em 8 mai. 2020.

HABERMAS, Jürgen. Teoria do agir comunicativo, 1: racionalidade da ação e racionalização social. São Paulo: WMF Martins Fontes, 2012.

HABERMAS, Jürgen. Teoria do agir comunicativo, 2: Sobre a crítica da razão funcionalista. São Paulo: WMF, Martins Fontes, 2012b.

ONU. Declaração do rio sobre meio ambiente e desenvolvimento. Disponível em: < https://cetesb.sp.gov.br/proclima/wpcontent/uploads/sites/36/2013/12/declaracao_rio_ma.pdf >. Acesso em: 28 mar. 2020.

JAQUES, Marcelo Dias. A TUTELA INTERNACIONAL DO MEIO AMBIENTE: UM CONTEXTO HISTÓRICO. Veredas do Direito, Belo Horizonte, v. 11, n 22, p. 299-315, $\mathrm{jul} / \mathrm{dez}, 2014$. 
LAVALL, Tauana Paula; OLSSON, Giovanni. Governança Global e o Desenvolvimento na sua Pluridimensionalidade: um olhar sobre a Agenda 2030 das Nações Unidas. Revista Direito \& Desenvolvimento, João Pessoa, v. 10, n1, p. 51-64, jan/jun, 2019.

MARCELLESI, Florent. Ecología política: génesis, teoria y práxis de la ideologia verde. Cuadernos Bakeaz, n 85. 2008

MARX, Karl. Contribuição à crítica da econômica política. São Paulo: Folha de S. Paulo, 2015.

MEADOWCROFT, James. Greening the State?. In: Comparative Enveironmental Politcs: Theory Practice and Prospects. The MIT Press, 2012. Disponível em: www.jstor.org/stable/j.ctt5vjs7f. Acesso em: 05 fev. 2021.

NAVES, Marcelo Tanos; PIRES, Gustavo Santiago. O Mercado de Créditos de Carbono e seus Aspectos Jurídicos. In: ROCHA, Fábio Amorim da. Temas relevantes no direito de energia elétrica. Tomo VI. Rio de Janeiro: Synergia, 2018, p. 522-537.

NOBRE, Marcos. A Teoria Crítica. $3^{\mathrm{a}}$ ed., Rio de Janeiro: Zahar, 2011.

NOBRE, Marcos. Curso Livre de Teoria Crítica. Campinas: Papirus, 2008 [E-book]

ONU. Declaração de Estocolmo sobre o ambiente humano -1972. Disponível em:

$<$ http://www.direitoshumanos.usp.br/index.php/Meio-Ambiente/declaracao-de-estocolmosobre-o-ambiente-humano.html>. 04 mai. 2020.

PAPA FRANCISCO. Carta Encíclica 'Laudato si' do santo padre Francisco - Sobre o cuidado da casa comum. Disponível em:

$<$ http://www.vatican.va/content/francesco/pt/encyclicals/documents/papa-

francesco_20150524_enciclica-laudato-si.html>. Acesso em 17 mai. 2020.

REPA, Luiz. Jürgen Habermas e o modelo reconstrutivo de teoria crítica. In: NOBRE, Marcos. Curso Livre de Teoria Crítica. Campinas: Papirus. 2008 [E-book]

SEQUINEL, Maria Carmen M. Cúpula mundial sobre desenvolvimento sustentável Joanesburgo: entre o sonho e o possível. Análise Conjuntural, v. 24, n. 11-12, p. 14, nov/dez, 2002

SILVA, Felipe Gonçalves. Democracia deliberativa. In: NOBRE, Marcos. Curso Livre de Teoria Crítica. Campinas: Papirus. 2008 [E-book]

STEFANIAK, Jeaneth Nunes. A insustentabilidade ambiental no Capitalismo: com análise da Encíclica Laudato Si - cuidando da Casa Comum. 1ed. Rio de Janeiro: LMJ Mundo Jurídico , 2016. 